\title{
Efeito do sal de ácido carboxílico sobre ninfas de Aphis gossypii Glover (1877) (Hemiptera: Aphididae)
}

\author{
Luis Gustavo Amorim Pessoa ${ }^{1}$, Willyam Eduardo Bonafede da Silva ${ }^{1}$, Muller de Paula \\ Ribeiro $^{1}$, Elisângela de Souza Loureiro ${ }^{1}$, Pamella Mingotti Dias ${ }^{2}$

\begin{abstract}
${ }^{1}$ Universidade Federal de Mato Grosso do Sul, Campus de Chapadão do Sul, Chapadão do Sul, Mato Grosso do Sul, Brasil. E-mail: luis.pessoa@ufms.br,willyam_seven@hotmail.com, mullerdepaularibeiro@hotmail.com, elisangela.loureiro@ufms.br

${ }^{2}$ Universidade Federal da Grande Dourados, Dourados, Mato Grosso do Sul, Brasil. E-mail: pamellamingotti@ hotmail.com
\end{abstract}

Recebido: 02/11/2017; Aceito: 08/11/2017.

\section{RESUMO}

Objetivou-se avaliar o efeito do sal de ácido carboxílico no controle de Aphis gossypi. Para instalação dos experimentos, adultos em fase reprodutiva foram coletados em plantas de algodão cultivadas em casa de vegetação e levados ao laboratório, sendo acondicionados em placas de Petri ( $6 \mathrm{~cm}$ de diâmetro) contendo discos foliares de algodão fixadas em uma fina camada solidificada de ágar-água. Os adultos permaneceram nos discos por 24 horas, sendo as ninfas produzidas utilizadas para aplicação dos tratamentos. Foram utilizadas ninfas de primeiro e terceiro ínstares. Os tratamentos foram aplicados com auxílio de torre de Potter sendo compostos por diferentes concentrações do sal de ácido carboxílico $\mathrm{BIO} \operatorname{ADD}(0,25 \% ; 0,5 \%$ e $0,75 \%)$, além do tratamento testemunha composto por água destilada esterilizada. Após as aplicações, as placas de Petri foram transferidas para câmaras climatizadas sendo mantidas a $25 \pm 1^{\circ} \mathrm{C}$, umidade relativa do ar de $70 \pm 10 \%$ e fotofase de 12 horas, avaliando-se a mortalidade e a eficiência em cada concentração do produto. O primeiro instar de A. gossypii foi o mais suscetível independente da concentração do produto testada e a concentração de $0,75 \%$ de BIO ADD proporcionou as maiores taxas de mortalidade e eficiência, independente do instar de A. gossypii.

Palavras-chave: pulgão do algodoeiro, controle alternativo, inseto sugador.

\section{Effect of carboxylic acid salt on Aphis gossypii Glover (1877) (Hemiptera: Aphididae) nymphs}

\section{ABSTRACT}

The objective of the present study was to evaluate the effect of carboxylic acid salt on the control of Aphis gossypii. For the installation of the experiments, adults in the reproductive phase were collected in cotton plants grown in a greenhouse, taken to the laboratory and placed in Petri dishes $(6 \mathrm{~cm}$ in diameter) containing cotton leaf discs fixed in a thin layer solidified with agar-water. The adults remained on the disks for 24 hours, and the nymphs were used to apply the treatments. First and third instar nymphs were used. The treatments were applied with the aid of a Potter tower and were composed of different concentrations of the BIO ADD carboxylic acid salt $(0.25 \%, 0.5 \%$ and $0.75 \%)$, in addition to the control treatment composed of sterilized distilled water. After the applications, the Petri dishes were transferred to the air-conditioned chamber and kept at $25 \pm 1{ }^{\circ} \mathrm{C}, 70 \pm 10 \%$ relative humidity and 12-hour photophase, evaluating the mortality and efficiency at each product concentration. The first instar of A. gossypii was the most susceptible regardless of the concentration of the tested product and the concentration of $0.75 \%$ BIO ADD provided the highest mortality and efficiency rates, regardless of the instar of A. gossypii.

Key words: cotton aphid, alternative control, sucking insect. 


\section{Introdução}

O pulgão (Aphis gossypi) Glover (1877) (Hemiptera: Aphididae) ataca diversas culturas, dentre elas o pepino, o pimentão, o tomate e a mais importante no Brasil, o algodão, devido ao seu valor econômico e social. É uma das primeiras pragas a aparecer na cultura do algodão, podendo ocorrer surtos durante todo o ciclo da planta. Preferem se alimentar sob folhas e brotos novos da planta, provocando encarquilhamento e deformações. $\mathrm{Na}$ fase inicial da lavoura ocasiona redução no desenvolvimento das plantas e, indiretamente, favorece a ocorrência de fumagina. Quando ocorrem ataques tardios podem causar caramelização da pluma devido ao desenvolvimento de fumagina sobre os excrementos da praga. $\mathrm{O}$ ataque do inseto tem sido bastante relacionado às condições climáticas como dias nublados, quentes e relativamente úmidos (PAPA, 2006; SILVIE et al., 2007).

Os pulgões também são responsáveis por transmitem mais de 50 vírus fitopatogênicos (PEÑA-MARTÍNEZ, 1992) os quais proporcionam perdas significativas em plantas suscetíveis. As doenças transmitidas por $A$. gossypii no algodoeiro são o vermelhão, o azulão e o mosaico das nervuras. As plantas infectadas com a virose mosaico das nervuras apresentam crescimento paralisado, com encurtamento dos internódios, permanecendo as bordas das folhas curvadas para baixo, em forma de guarda-chuva e com rugosidades no limbo foliar; quando a incidência desta doença acontece na fase inicial e de maneira severa, provoca danos totais à produção (PAPA, 2006; SANTOS, 2007; SILVIE et al., 2007).

A forma mais comum para restringir o crescimento populacional de A. gossypii é o uso de inseticidas sintéticos e sistêmicos (via solo ou de contato via aplicação foliar) (TORRES; SILVA-TORRES, 2008). O controle químico dessa praga, apesar de provocar efeitos adversos ao agroecossistema, ainda tem sido um dos principais métodos usados pelos agricultores para o manejo dessa praga (QUINTELA et al., 1991). Atualmente, uma das alternativas que tem sido utilizadas em substituição ao uso dos inseticidas no controle das pragas é o uso de extratos naturais de plantas juntamente com produtos de baixo custo como sabão; fórmulas de fácil aquisição e baixo custo (SILVA et al., 2011). Alguns efeitos deletérios sobre os insetos são atribuídos aos sabões. Eles podem interferir a nível celular provocando o rompimento das membranas celulares e interferindo no processo de respiração dos insetos e no seu desenvolvimento (BUTLER et al., 1993).

Dessa forma, os sabões demonstram potencial para minimizar os problemas com pragas além de poder reduzir as aplicações de inseticidas, podendo ser utilizado dentro das táticas do Manejo Integrado de
Pragas (MIP), envolvendo a utilização de produtos alternativos. Assim, este trabalho objetivou avaliar a eficiência de sabão a base de sal de ácido carboxílico no controle de A. gossypii.

\section{Material e Métodos}

O experimento foi conduzido utilizando o produto comercial de uso agrícola $\mathrm{BIO} \mathrm{ADD}^{\circledR}$, sal de ácido carboxílico [5\%], sobre o pulgão A. gossypii. Para criação do pulgão e instalação dos bioensaios utilizou-se plantas de algodão cultivadas em vasos de 5 litros, mantidos em casa de vegetação revestida com tela antiafídio. Foram semeadas quatro sementes por vaso (com distribuição equidistantes entre elas) e, após a emissão das primeiras folhas verdadeiras foi feito o desbaste deixando as duas plantas mais vigorosas em cada vaso.

Os pulgões utilizados foram coletados em áreas comerciais de cultivo de algodão e transferidos para as plantas em casa de vegetação. Durante o período de criação houve cuidado para evitar proliferação do complexo de parasitoides que ocorrem naturalmente sobre essa espécie.

Para instalação dos experimentos, adultos na fase reprodutiva foram coletados nas plantas acondicionadas em casa de vegetação e levados ao laboratório. Foram preparadas placas de Petri ( $6 \mathrm{~cm}$ de diâmetro), cada uma contendo uma lâmina solidificada de ágar-água (a 20\%) e um disco foliar de $3 \mathrm{~cm}$ de diâmetro do mesmo cultivar de algodão onde os insetos foram criados (folhas do terço médio), com sua face adaxial para cima. Oito adultos permaneceram em cada disco foliar por 24 horas, sendo as ninfas por eles produzidas utilizadas para aplicação dos tratamentos. Antes da infestação as folhas foram desinfestadas em álcool $70 \%$, hipoclorito $1 \%$ e água destilada, posteriormente secas com papel absorvente.

Os tratamentos foram aplicados com auxílio da torre de Potter regulada à pressão de $15 \mathrm{lb} / \mathrm{pol}^{2}$ propiciando aplicação de 1,5 a $2,0 \mathrm{mg}$ de calda $/ \mathrm{cm}^{2}$. Foram utilizados insetos no primeiro e terceiro ínstares sobre os quais foram aplicadas caldas contendo diferentes concentrações do $\mathrm{BIO} \operatorname{ADD}^{\circledR}(0,25 \% ; 0,50 \%$ e $0,75 \%)$, além do tratamento testemunha composto por água destilada esterilizada. Após as aplicações, as placas de Petri foram transferidas para a câmara climatizada tipo BOD a $25 \pm 1{ }^{\circ} \mathrm{C}$, umidade relativa de $70 \pm 10 \%$ e fotofase de 12 horas, sendo mantidas invertidas, para simular o posicionamento real dos insetos nas plantas.

As avaliações foram realizadas a cada 24 horas pós aplicação, durante duas semanas, com auxílio de microscópio estereoscópico, contando-se os insetos mortos e calculando a mortalidade acumulada e total. $\mathrm{O}$ delineamento utilizado foi o inteiramente casualizado 
com 10 repetições, cada uma contendo 6 insetos. Para análise, os dados de mortalidade foram transformados em $\operatorname{arsen}(\mathrm{x} / 100)^{1 / 2}$, sendo submetidos à análise da variância e as médias comparadas pelo teste de ScottKnott $(\mathrm{P}<0,05)$. Também se calculou a eficiência através da fórmula de Abbott (ABBOTT, 1925).

\section{Resultados e Discussão}

Houve diferenças significativas na mortalidade de $A$. gossypii entre as concentrações do $\mathrm{BIO} \mathrm{ADD}^{\circledR}$ testadas e também entre os ínstares. Para o primeiro instar houve diferença significativa para todas as concentrações, observando-se a maior taxa de mortalidade na maior concentração. No terceiro instar não houve diferença entre as concentrações $0,75 \%$ e $0,50 \%$; porém estas proporcionaram mortalidade superior a menor concentração (Tabela 1). Comparando-se os diferentes ínstares de A. gossypii houve diferenças entre as mortalidades onde o primeiro instar apresentou maior suscetibilidade ao $\mathrm{BIO} \mathrm{ADD}^{\circledR}$ em todas as concentrações testadas (Tabela 1).

Quanto à eficiência, verificou-se para os dois ínstares que a concentração de $0,75 \%$ do $\mathrm{BIO} \quad \mathrm{ADD}^{\circledR}$ proporcionou o maior controle de A. gossypii. Para ninfas de primeiro instar verificou-se que a maior concentração foi $39,6 \%$ e $53,4 \%$, superior às concentrações $0,50 \%$ e $0,25 \%$, respectivamente; para ninfas de terceiro instar a maior concentração proporcionou resultados $15,1 \%$ e $23,3 \%$ superiores às concentrações $0,50 \%$ e $0,25 \%$, respectivamente (Tabela 2 ).

Comparando as eficiências entre os dois ínstares, verificou-se que o produto proporcionou melhor resultado para ninfas de primeiro instar em relação às de terceiro sendo $37,77 \%, 13,18 \%$ e $7,61 \%$ superiores aos valores observados para ninfas de terceiro instar para as concentrações $0,75 \% \quad 0,50 \%$ e $0,25 \%$, respectivamente (Tabela 2). Para os dois ínstares foi observado efeito residual diferente entre as concentrações de BIO ADD.

No primeiro instar as concentrações $0,75 \%$ e $0,25 \%$ foram as que proporcionaram efeito por mais tempo. Para a concentração $0,75 \%$ o maior incremento na mortalidade ocorreu até o $7^{\circ}$ dia após a exposição; para a concentração $0,50 \%$ até o $5^{\circ}$ dia; e para a $0,25 \%$ até o $4^{\circ}$ dia (Figura 1).
Para o terceiro instar as concentrações $0,75 \%$ e $0,50 \%$ foram as que proporcionaram efeito residual por mais tempo. Para a concentração $0,75 \%$ o incremento na mortalidade ocorreu até o $8^{\text {o }}$ dia após a exposição; após esse período não se verificou mais mortalidade. Para a concentração $0,50 \%$ o aumento na mortalidade ocorreu até o $8^{\circ}$ dia; e para a $0,25 \%$ verificou-se mortalidade apenas até o $5^{\mathrm{o}}$ dia, não se verificando mais mortalidade após esse período (Figura 2).

Tabela 2. Eficiência (\%) das diferentes concentrações de BIO ADD sobre ninfas de Aphis gosypii.

\begin{tabular}{ccc}
\hline Tratamento & $1^{\underline{0}}$ instar & $3^{\underline{0} \text { instar }}$ \\
\hline Testemunha & - & - \\
BioAdd $(0,25 \%)$ & 10,34 & 2,73 \\
BioAdd $(0,50 \%)$ & 24,14 & 10,96 \\
BioAdd $(0,75 \%)$ & 63,79 & 26,02 \\
\hline
\end{tabular}

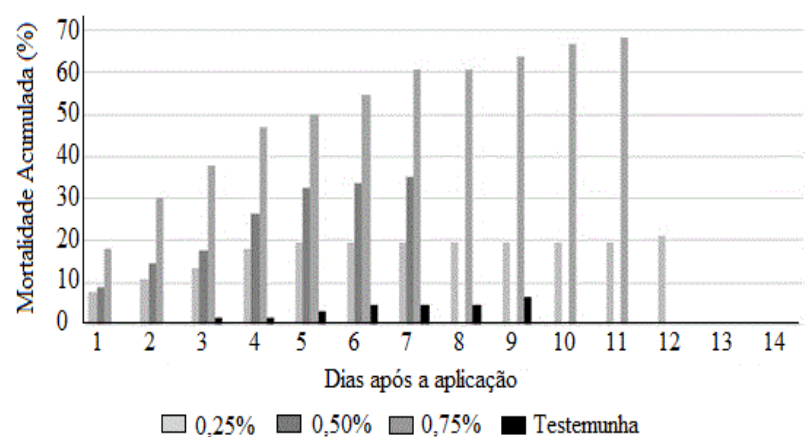

Figura 1. Mortalidade acumulada (\%) de ninfas de primeiro instar de Aphis gossypii em função da exposição às diferentes concentrações de $\mathrm{BIO} \mathrm{ADD}^{\circledR}$.

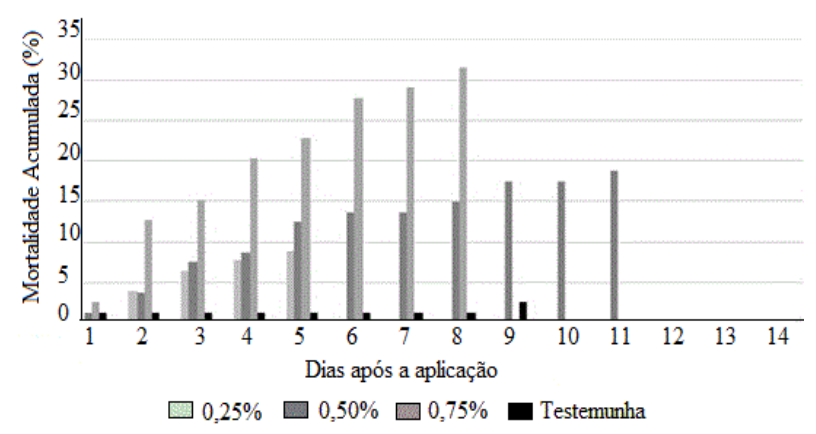

Figura 2. Mortalidade acumulada (\%) de ninfas de terceiro instar de Aphis gossypii em função da exposição às diferentes concentrações de BIO ADD ${ }^{\circledR}$.

Tabela 1. Mortalidade (\%) $( \pm \mathrm{EP})$ de ninfas de Aphis gossypii expostas aos diferentes tratamentos.

\begin{tabular}{lccc}
\hline Tratamento & $1^{\circ}$ instar & $3^{-}$instar & CV (\%) \\
\hline Testemunha & $6,45 \pm 0,26 \mathrm{dA}$ & $2,67 \pm 0,22 \mathrm{bA}$ & 12,18 \\
BIO ADD $(0,25 \%)$ & $21,21 \pm 1,05 \mathrm{cA}$ & $8,97 \pm 0,72 \mathrm{bB}$ & 16,07 \\
BIO ADD $(0,50 \%)$ & $35,29 \pm 1,44 \mathrm{bA}$ & $18,75 \pm 0,92 \mathrm{aB}$ & 10,45 \\
BIO ADD $(0,75 \%)$ & $68,18 \pm 2,49 \mathrm{aA}$ & $31,64 \pm 1,24 \mathrm{aB}$ & 19,5 \\
\hline CV $(\%)$ & 12,33 & 14,74 & -
\end{tabular}

Médias seguidas pela mesma letra minúscula na coluna e maiúsculas na linha não diferem significativamente entre si. ${ }^{1}$ Para análise dados transformados em arsen $(\mathrm{x} / 100)^{1 / 2}$. 
Os sabões podem ser derivados de sais de sódio de ácido carboxílico, como o $\mathrm{BIO} \mathrm{ADD}^{\circledR}$. O mecanismo de ação dos sabões sobre os pulgões não está totalmente elucidado, podendo agir de três maneiras: em primeiro lugar, podem atuar por penetração dos ácidos graxos através da cutícula do inseto, dissolvendo ou rompendo as membranas celulares, perturbando a integridade das células causando seu colapso, destruindo as funções respiratórias, resultando em desidratação e morte do inseto; em segundo lugar, podem agir como reguladores de crescimento do inseto, interferindo com o seu metabolismo celular e produção de hormônios de crescimento durante a metamorfose; e por último, podem bloquear os espiráculos do inseto, interferindo na respiração (BUTLER et al., 1993; CRANSHAW, 2003).

Outros efeitos podem ser observados em diferentes grupos de insetos como a quebra da camada de cera presente no exoesqueleto (causando a morte pela excessiva perda de água), inibição enzimática além de promover remoção dos indivíduos das folhagens e/ou repelência (ENDERSBY; MORGAN 1991; BUTLER et al., 1993; VILLAS BOAS et al.,1997; CRANSHAW, 2003; CURKOVIC; ARAYA, 2004; COLLARD; EBERLY, 2005).

Osborne (1984) observou que soluções de sabão a 6,2 ou $12,4 \mathrm{~g} / \mathrm{L}$ foram tão eficientes quanto acaricidas pertencentes aos organoclorados para o controle de Tetranychus urticae (Koch, 1836) (Acari: Tetranychidae) em Schefflera actinophylla (Endl.) Harms (=Brassaia actinophylla) em casa de vegetação, além de apresentarem certo efeito residual sobre a infestação e não apresentarem efeito fitotóxico.

Frantz (1984) trabalhando com soluções de sabão verificou eficiência entre 80 e $86 \%$ sobre Stephanitis pyrioides (Scott, 1874) (Hemiptera: Tingidae) em Rhododendron sp.. Gill e Raupp (1989) observaram redução entre 91 e $88 \%$ na população de $S$. pyrioides em azaléia, utilizando soluções de sabão com concentrações de 2,5 e $5,0 \%$. A eficiência superior à verificada no presente trabalho pode ter ocorrido pela diferença de concentração, 5 e 10 vezes maior, em relação àquelas de BIO ADD testadas. Os resultados obtidos ainda são preliminares, porém mostram o potencial do BIO ADD em reduzir a população do pulgão do algodoeiro, podendo compor o rol de estratégias para manejar essa praga.

\section{Conclusões}

O primeiro instar de A. gossypii foi mais suscetível a ação do BIO ADD, nas três concentrações testadas.

A concentração de $0,75 \%$ de BIO ADD proporcionou as maiores taxas de mortalidade $\mathrm{e}$ eficiência, independente do instar de A. gossypii.

\section{Agradecimentos}

A empresa Bio Controle pela cessão do produto para os testes sobre os insetos

\section{Referências Bibliográficas}

ABBOTT, W.S. A method of computing the effectiveness of an insecticide. Journal of Economic Entomology, Oxford, United Kingdom, v. 18, p. 265-267, 1925.

BUTLER J. R., G. D.; HENNEBERRY, T. J.; STANSLY, P. A.; SCHUSTER, D. J. Insecticidal effect of selected soaps, oils and detergents on the sweetpotato whitefly (Homoptera: Aleyrodidae). Florida Entomologist, Lutz, Flórida, v. 76, p. 161-167, 1993.

COLLARD, J.; EBERLY, D. Integrated Pest Management: a toolkit of practices and principles. Arbor Age, Camberra, Austrália, v. 25, p. 26-28, 2005.

CRANSHAW, W. S. Insect control: Soaps and detergents. Home \& Garden, Colorado State University, n. 5547, 2003. Diponivel

em:http://www.ext.colostate.edu/pubs/insect/05547.html.

Acesso em: 10 maio 2017.

CURKOVIC, T.; ARAYA, J. E. Acaricidal action of two detergents against Panonychus ulmi (Koch) and Panonychus citri (Mcgregor) (Acarina: Tetranychidae) in the laboratory. Crop Protection, Cambridge, United Kingdom, v. 23, p. 731733, 2004.

ENDERSBY, N. M.; MORGAN, W. C. Alternatives to synthetic chemical insecticides for use in crucifer crops. Biological Agriculture and Horticulture, London, United Kingdom, v. 8, p. 33-52, 1991.

FRANTZ, V. Insect pest control in the greenhouse: alternatives to commercial toxins. Proceedings Indiana Academy of science, Indianapolis, USA, v. 94, p. 98, 1984.

GILL, S. A.; RAUPP, N. Control of azalea lacebug using insecticidal soap and neem. Journal American Rhododendron Society, New York, USA, v. 43, n. 4, p. 216217, 1989.

LAVOR, M. T. F. C.; MANO, A. R. O.; FURTADO, R. F.; CANUTO, K. M.; BLEICHER, E. Atividade inseticida das sementes do cumaru contra Aphis craccivora Koch. Horticultura Brasileira, Vitória da Conquista-BA, v. 23, n. 2, R. 146, p. 360, 2005.

LAREW, H. G., AND J. C. LOCKE. Repellency and toxicity of a horticultural oil against whiteflies on chrysanthemum. HortScience, Alexandria, USA, v. 25, n. 11, p. 1406-1407, 1990.

OSBORNE, L. S. Soap spray: an alternative to a conventional acaricide for controlling the twospotted spider mite (Acari: Tetranychidae) in greenhouses. Journal of Economic Entomology, Oxford, United Kingdom, v. 77, n. 3, p. 734737, 1984.

PAPA, G. Pragas e seu controle. In: ALGODÃo: pesquisas e resultados para o campo. Cuiabá-MT: FACUAL, 2006. p 2006-239. 
PEÑA-MARTÍNEZ, R. Identificación de afidos de importância agricola. In: URIAS, C. M.; RODRÍGUEZ, R. M.; ALEJANDRE, T. A. Afidos como vectores de virus en México. Montecillo: Centro de Fitopatologia, v. 2. 1992. p.1135.

QUINTELA, E. D.; NEVES, B. P.; QUINDERÉ, M. A. W.; ROBERTS, D. W. Principais pragas do caupi no Brasil. Goiânia-GO: Embrapa-CNPAF, 1991. 37 p.

SANTOS, W. J. Manejo das Pragas do Algodão com Destaque para o Cerrado Brasileiro. In: Freire, E. C. Algodão: no cerrado do Brasil. Brasília-DF: Associação Brasileira dos Produtores de Algodão, 2007. 918 p.

SILVA, D. C. O.; ALVES, J. M. A; ALBUQUERQUE, J. A. A.; LIMA, A. C. S; VELOSO, M. E. S.; SILVA, L. S. Controle de insetos-praga do feijão-caupi na savana de Roraima. Revista Agro@mbiente, Boa Vista-RO, v. 5, n. 3, p. 212-219, 2011. Disponível em: https://revista.ufrr.br/agroambiente/article/view/605/624. Acesso em: 06 set. 2016.
SILVIE, P.; BÉLOT, J. L.; MICHEL, B. Manual de identificação das pragas e seus danos no cultivo de algodão. 2. ed. Cascavel-PR: COODETEC/CIRAD-CA, 2007. 120 p. (Boletim Técnico, 34).

TORRES, J. B.; SILVA-TORRES, C. S. A. Interação entre inseticidas e umidade do solo no controle do pulgão e da mosca-branca em algodoeiro. Pesquisa Agropecuária Brasileira, Brasília-DF, v. 43, n. 8, p. 949-956. 2008.

VILLAS BÔAS, G. L.; FRANÇA, F. H.; ÁVILA, A. D.; BEZERRA, I. C. Manejo integrado da mosca-branca Bemisia argentifolii. Brasília-DF: Embrapa-CNPH, 1997. 11 p. (Circular Técnica, 9). 